\title{
Stances towards euthanasia
}

\author{
Tim Helme, formerly Registrar in Forensic Psychiatry, Ashen Hill Unit, Hellingly \\ Hospital, Hailsham, East Sussex
}

Active voluntary euthanasia may be defined as the deliberate taking of a patient's life, or the facilitation of his or her suicide, with the informed consent and at the express request of the patient. It may therefore be distinguished from passive euthanasia, when no positive step is taken to hasten death but when potentially life-saving measures are intentionally withheld, and also from non-voluntary euthanasia, when the patient is unable to participate in the decision, or is incapable of providing an adequately informed consent.

A change in the law on active euthanasia within the foreseeable future appears inevitable. In this country, national opinion polls have established that the proportion of the population agreeing with the statement that "the law should allow adults to receive medical help to an immediate peaceful death if they suffer from an incurable physical illness that is intolerable to them, provided that they have previously requested such help in writing" has progressively increased as follows:

$\begin{array}{ll}1976 & 69 \% \\ 1985 & 72 \% \\ 1989 & 75 \%\end{array}$

Similarly in Holland, Leenan quotes the percentages below as those who have been found to be in favour of active euthanasia (Leenan, 1990).

$\begin{array}{ll}1966 & 39.9 \% \\ 1975 & 52.6 \% \\ 1979 & 51 \cdot 4 \% \\ 1980 & 52.4 \% \\ 1981 & 53.8 \% \\ 1985 & 67 \% \\ 1986 & 67 \%\end{array}$

Because, in abstract terms, euthanasia can be seen as an example of the acceptance of, or insistence on, a voluntary act of separation, this shift in attitudes may be viewed as in keeping with the change in thinking behind other social legislation such as the Suicide Act 1961, the Abortion Act of 1967 and the Divorce Reform Act 1969. While at face value, or "task level", the actual situations are obviously different, they may be seen as in some ways comparable and as perhaps having shared psychological determinants.

\section{The traditional position}

The traditional position has been comprehensively restated in the report by the British Medical Association of May 1988, produced as a response to the resolution passed at its Annual Representative Meeting in 1986 that it needed to re-examine its policy on euthanasia. It reiterated the view previously expounded in such documents as the Anglican booklet $O n$ Dying Well, written over a decade before, that the distinction between active and passive euthanasia is morally significant and sufficiently important that no change in the law should be advocated (Church Information Office, 1975).

The "basic assumption" appears to be that of "dependency": that the appropriate stance is one of passive submission to the will of God, or to the course of nature, and that therefore while unnecessary suffering should always be alleviated, this fundamental stance should not be challenged.

The difficulty is that while the majority of deaths may be managed perfectly satisfactorily under such an assumption, it would clearly be untrue to claim that this is possible for all. It is interesting to note that while many philosophers have apparently argued in favour of active euthanasia for those deaths which are accepted as involving an intolerable degree of suffering, the "intuitions" of the medical profession have largely been opposed to it. This could either reflect the greater and more intimate experience of doctors in the realities of terminal care, or represent a defensive and omnipotent fantasy on the part of the profession, associated with a manic and controlling contempt for the suffering of patients, invoked in order to protect doctors themselves from the pain involved. The injunction against active euthanasia is therefore perhaps understandably attacked by some as a "restrictive solution", imposed, or at least supported, by doctors partly in order to defend their own interests. Alternatively, as the BMA suggests, others may consider that the taboo is not only appropriate but may be justified as necessary or "required", because active euthanasia legitimately needs to be "avoided", due to the threat of slipping into the "calamity" represented by Nazi Germany. Whether this fear is realistic is open to debate. 


\section{The Dutch alternative}

The Dutch alternative diminishes the significance of the distinction between active and passive euthanasia, and emphasises autonomy rather than passive acceptance (Leenan, 1990; Rigter et al, 1988).

The Dutch Penal Code prohibits both euthanasia (Section 293) and assisted suicide (Section 294), and any physician administering euthanasia remains potentially punishable. Euthanasia has not therefore been legalised, but guidelines have been established whereby it is understood that practitioners will not be prosecuted provided that certain criteria are met. Briefly, these are that the patient should be fully informed and should consistently and freely consent, and that the practitioner should be convinced that there is no reasonable alternative, should have consulted with a suitable colleague and should keep adequate records. It is said that about $2 \%$ of Dutch deaths take place under this procedure (Rigter $e t$ al, 1988).

The emphasis on autonomy in the place of dependent acceptance, albeit with the continuing threat of punishment, is reminiscent of the shift from Fairbairn's Stage of Infantile Dependence to his Transitional Stage of Quasi-Independence. The accusation of omnipotence in the fantasy perhaps no longer applies to the profession but may relate to narcissistic object relations on the part of the patient or the individual practitioner. Put another way, the demand for autonomy and independence may have a compulsive quality which over-values the virtues of self-determination, at the possible expense of the gentler and more trusting aspects of the personality, and at risk of the neglect or abuse of the emotions and needs of others, in the interests of a purely individual freedom. There may therefore be a balance to be achieved in order to establish sufficient privacy and privilege to protect the rights of the patient and the intimacy of the consultation, but not to the extent of permitting such exclusive liberty that autonomy degenerates into anarchy.

The "basic assumption" may be identified not as "dependency", or even one of "fight or flight" as perhaps with the isolated suicide, but as a collusive "pairing" in potential opposition to the rest of society. There is a danger that conflicts and ambivalence over dying may not be adequately worked through, but avoided, with aggression being externalised and projected onto the surviving friends and relations.

\section{The bureaucratic option}

Following Fairbairn's terminology, the bureaucratic option would be intended to obviate the dangers of isolationism and to prevent the potential abuse of permissive legislation by allowing for a stance equivalent to his Stage of Mature Dependence. Rather than simply permitting patients and practitioners greater freedom while leaving the situation ambiguous with the latter potentially punishable after the event, this third stance would be intended to clarify the position in anticipation of the patient's death.

The Mental Health Act 1983 allows for a patient to appeal to a Mental Health Review Tribunal against any compulsory treatment imposed by his psychiatrist. The Tribunals therefore provide a mechanism, and possible model, for allowing patients to challenge the decisions of their practitioners and, conversely, to confirm and legitimise the decisions and recommendations of those practitioners where appropriate. This system could presumably be transposed to situations involving active euthanasia.

The Mental Health Review Tribunals consist of three members: a chairman who is a lawyer; a medical practitioner, usually a psychiatrist, with an expertise in the treatment of mental illness; and a layman. However, if a system of Euthanasia Tribunals were to be instituted, it might be considered appropriate to have a rather larger number of people involved, perhaps:

(a) a chairman, with a suitable legal qualification and experience

(b) a medical practitioner, with an expert knowledge of the illness from which the patient suffers

(c) a psychiatrist, in order to exclude the presence of treatable mental illness, and to provide a psychotherapeutic input if required

(d) a solicitor or social worker, to examine the social and especially the financial implications of the death being contemplated, in order to minimise the possibility of duress

(e) a layman, to provide a balancing and general perspective.

As with all bureaucratic solutions, such a system would be cumbersome, expensive, time-consuming and invasive of privacy. However such a stance would have the advantage of providing a legal framework for containing the anxieties involved in the more uncertain cases so that active euthanasia could then take place in a manner that was dignified and open rather than surreptitious and furtive. It would therefore provide the opportunity to integrate and confirm the patient as an accepted member of society, rather than tending to isolate and excommunicate him as he dies. It would also ensure that the decision to die was only elected after due consideration, rather than taken precipitately. While the mechanism of a patient appealing to a Tribunal against the intention of his physician to preserve his life would enable active euthanasia to take place, it would at the same time have the advantage of endorsing the value of the traditional medical role. 


\section{Proposals for legislation}

While the vast majority of deaths should presumably continue to take place under present legislation, two suggestions can be offered from the Mental Health Act for possible extrapolation to the subject of terminal care.

(a) A Terminal Care Commission could be instituted, by the Secretary of State on the model of the Mental Health Act Commission, in order to review the provision of terminal care and to establish guidelines for good practice. The Commission could then be approached, either by practitioners or by patients or relatives, and second opinions provided on request.

One possibility would be to restrict the remit of the Commission to passive euthanasia. Thus the Commission might be approached by, for instance, the relations of a dementing patient, who was no longer able to give an informed consent, in order to provide support for a non-treatment decision. The effect of the Commission, like that of the hospice movement, would be expected to have a beneficial influence on the thinking of the profession as a whole, and of public opinion in general, in favour of anticipatory terminal care and away from philosophies of inappropriate intervention or chronic "warehousing" (Miller \& Gwynne, 1972).

(b) The second suggestion from the Mental Health Act is the one discussed above that patients should be allowed to appeal to Euthanasia Tribunals for active interventions to end their lives, provided that they:

(i) understood the nature of the application that they were making

and (ii) had an enduring and a considered wish to die, and were not under any form of external duress or coercion, either for financial or for other reasons

and (iii) were suffering from a condition which was both permanent and incurable, and which was causing them significant distress

and (iv) were not suffering from any distortion of judgement due to temporary or treatable psychiatric illness.

\section{Conclusion}

The editorial which accompanied the BMA's report in 1988 was entitled 'Not the last word on Euthanasia' (Higgs, 1988). This was certainly apposite, as Ludovic Kennedy's recent 'Counterblast' indicates (Kennedy, 1990). The profession needs to reflect on its possible stances unless it is prepared to ignore, and be ignored by, the pressure of public opinion, and the Mental Health Act represents one possible model by which it could respond to this pressure.

\section{References}

BRITISH MEDICAL Association (1988) Euthanasia: report of the working party to review the British Medical Association's guidance on euthanasia. London: BMA.

Church Information OfFice (1975) On Dying Well: an Anglican contribution to the debate on euthanasia. Church Information Office, Church House, Great Smith Street, London SWIP 3NZ.

HigGs, R. (1988) Not the last word on euthanasia. British Medical Journal, 296, 1348.

KenNedy, L. (1990) Euthanasia: The Good Death. Counterblasts No. 13. London: Chatto \& Windus.

LEENAN, H. J. J. (1990) Euthanasia in the Netherlands. In: Medicine, Medical Ethics and the Value of Life (ed. Peter Byrne). Chichester: John Wiley.

Miller, E. J. \& GWynne, G. V. (1972) A Life Apart. London: Tavistock Publications.

Rigter, H., Barst-Eilers, E. \& Leenan, H. J. J. (1988) Euthanasia across the North Sea. British Medical Journal, 297, 1593-1595.

A full list of references is available from the author. 